\title{
Energy Flexibility in the Power System: Challenges and Opportunites in Philippines
}

\author{
Joy Dalmacio Billanes, Zheng Ma and Bo Nørregaard Jørgensen \\ Center for Energy Informatics, Mcersk Mc-Kinney Møller Institute, University of Southern Denmark, Campusvej 55, Odense M 5230, \\ Denmark
}

Received: August 22, 2017 / Accepted: August 30, 2017 / Published: September 30, 2017

\begin{abstract}
Energy flexibility can address the challenges of large scale integration of renewable energy resources and thereby increasing imbalance in the power system. Flexible power system can provide reliable supply, low electricity cost and sustainability. Various situations and factors influence the adoption of the flexibility solutions, such as flexible electricity generation, demand-response, and electricity storage. This paper tries to analyze the current energy flexibility solutions and the factors that can influence the energy flexibility adoption. This paper takes Philippines as case study to provide an overview of the current condition of the Philippines' power system and discuss the energy flexibility in the Philippines' power system. A further discussion and recommendation is conducted in the end of the paper.
\end{abstract}

Key words: Energy flexibility, demand-response, Philippines power system, renewable generation.

\section{Introduction}

The rapid increase in population size affects the environment and the reliability of the power system. Different countries utilize renewable energy resources to increase the supply of energy and reduce GHG (greenhouse gas) emissions. The Europe Union targets to increase $20 \%$ in energy efficiency, $20 \%$ increase in generation of renewable energy resources and 20\% reduction of GHG emission by 2020 [1]. For example, countries like Denmark, Portugal and Ireland utilize wind resources while other countries have adopted photovoltaic solar panels, wind power or wave generation as the main renewable energy resources in their countries [2]. However, it is a challenge to integrate renewable energy resources in the power system because of its intermittent nature and the thereby increased imbalance in the system. Consequently, the increasing energy demand and resource variability and instability require flexibility in

Corresponding author: Zheng Ma, associate professor, research fields: smart energy management and innovation. the energy system [3].

Energy flexibility can maintain the balance between energy supply and demand in the power grid. "Flexibility" is defined by the Oxford Dictionary as the "ability to change to suit new conditions or situations". The "energy system flexibility" is defined as: The ability of the system to manage the variability of energy resources and demand while maintaining the reliability of the grid [4]. Lannoye et al. [2] define flexibility as "the ability of a system to deploy its resources to respond to changes in the net load".

Flexibility reduces congestion and improves reliability and security in the grid, thereby reducing electricity prices and improving energy market performance [5]. Flexible energy power system enables to avoid technical failures [6] and responds quickly to any change occuring in the power system [7]. In general, flexibility has a potential to minimize energy cost, balance the energy supply and distribution as well as to increase the generation of RES (renewable energy resources) and maintain the stability of grid. 
However, the reasons and solutions for the energy flexibility across countries vary due to the maturity of the energy system and the renewable energy resources potential. Other factors might also influence the national energy flexibility development, such as economic and climate situations. Therefore, by examining the current existing solutions for the flexibility in the power system and applying a case of the power system in Philippines, this paper aims to develop a framework for the national energy flexibility adoptions with the integration of the national energy flexibility potentials and influential factors. The recommendation for the flexibility achievement in the power system in Philippines is provided in this paper.

\section{Solutions for the Energy Flexibility}

Flexibility in the power system became a priority of many countries due to various national reasons like growing population size or international reasons like global warming. Energy flexibility can happen across all sectors of the power system (generation, transmission, distribution and demand-side) [8]. There are different solutions to attain flexibility in the power system, such as grid infrastructure, energy generation units, energy storage, and DR (demand response) [9].

\subsection{Flexibility in the Energy Generation}

Flexible energy generation means that the generation integrates renewable resources to be able to respond to the energy demand, e.g. fast-ramping generation resources provide flexibility and enable generate energy on demand [6]. Flexible energy resources are able to hold energy levels for longer period, have greater ramp rates and able to adjust quickly to any change in condition of the power system [4].

The integration of distributed energy resources fulfills the increasing energy demand and enhances energy flexibility [7]. Energy consumers/prosumers install distributed generation for own energy consumption or to sell the excess electricity to the grid. Distributed generation is a renewable power generation solution (integrates e.g. PV systems) connected to the distribution network or micro grid [10]. Storage devices, production schedules and locations in the network influence the flexibility in the generation [11]. The appropriate size and location of the distributed generation helps to reduce power loss [12].

\subsection{Flexibility in the Grid Infrastructure}

The transmission and distribution infrastructure can provide flexibility in the power system by balancing the production and consumption over larger distances [13]. Moreover, flexible transmission systems maintain the reliability standard at reasonable operation costs [14]. Providing sufficient transmission capacity and interconnections (AC lines or HVDC (high-voltage direct current) cables) between market areas or regions enhance the transmission flexibility, reliability and improve power-sharing control [8]. Deployment of power flow controlling devices (PFCs), such as PSTs (phase shifting-transformers) and HVDC enhances flexibility in for instance European transmission system [15]. The flexibility in the transmission system to integrate large-scale renewable energy resources is determined according to adequacy and security evaluations of the grid infrastructure [16].

Flexibility also occurs in the distribution systems by utilizing the abilities of the electricity consumers' (commercial, industrial or residential) flexibility [17]. Flexible distribution network allows the utilities to meet the local electricity demand by creating a networked distribution grid [18]. The TSOs (transmission system operators) [23] and DSOs (distribution system operators) [16] are responsible for maintaining the reliability and flexibility of the grid.

\subsection{DR (Demand Response)}

Prosumers are both consumers and producers of energy who provide flexibility by controlling building appliances [4]. Energy prosumers play an active role in achieving flexibility in the demand side. Flexible demand-side enables to integrate and balance the 
renewable energy generation to energy market demand [13]. Demand response reduces peak load, power outage, electricity cost, and improves social welfare [9]. Power balance issue or network constraint can be solved through peak shaving and demand response [17]. Peak shaving reduces the peak demand by controlling the energy consumption.

DR motivates customers to participate in generation-load balance [19]. Time and financial incentives influence the flexibility in energy consumption of consumers (energy habits and preferences) [9, 20]. Devices like smart meters and net meters are essential devices for the DR programs. Smart meters and net meters allow energy prosumers to participate in the TOU (time-of-use) and buy-back energy program. Buy-back energy program allows consumers to import and export energy from external grid [21].

\subsection{Energy Storage}

The intermittent characteristics of renewable energy push the energy system to utilize energy storage to achieve the required flexibility [22]. The installation of energy storage increases despite its high cost [19]. Shared energy storage system achieves high return of investment [24]. Moreover, shared energy storage systems allow the optimization and exchanging minimal information among users [24]. Optimizing the energy storage system's schedule and other building technologies can reduce energy consumption [25].

Energy storage systems support the power system to store excess energy and release the stored energy when energy supply is insufficient [24]. In addition, energy storage is also useful for electricity prosumers who have installed photovoltaic system [26]. Energy storage provides flexibility in the transmission, distribution and demand side [25]. The performance of each energy storage system varies. For example, a cost-effective pump hydro storage [21] provides flexibility by pumping the water during low demand (e.g. at night) and discharging the stored water to generate electricity during high demand period [18]. However, pump hydro storage requires a geographical area [22] with adequate elevation.

\subsection{Energy Market Operation}

There are two types of electricity markets: wholesale and retail. Aggarwal and Orvis (2016) [17] argue that market operation achieves flexibility by shortening the dispatch schedules, improved weather forecasting and consolidate balancing areas. Shortening dispatch schedules can allow the grid to change more rapidly in supply from variable clean energy sources to response the electricity demand. With improved weather forecasting, the commitment, dispatch, and transmission schedules can be updated more frequently to reduce the need for operating reserves.

Electricity suppliers act on behalf of the retail customers [9] to participate in the wholesale market [17]. Electricity suppliers buy electricity from the wholesale market and sell it in the retail market [10]. The DSOs are responsible of delivering the electricity purchased by the electricity suppliers to the consumers while maintaining grid stability [27].

\section{Influential Factors to the Energy Flexibility}

Key stakeholders (government, grid operators, distributors, and consumers/prosumers) play a major rule in the energy flexibility [28]. For example, energy consumers/prosumers are concerned about reducing electricity bills [29]. Lack of investments, delay in new infrastructure development and grid equipment affect the grid's reliability [17]. Other factors influencing the flexibility in the power system include technology readiness (social influence), incentives and regulation.

Understanding the technology readiness of end-users would improve flexibility in the grid. The acceptance of technology depends on the cost and benefits that the community would get in participating the program and by the people involved in the decision making process [28]. 
Changing the consumers' behaviors is one of the challenges in implementing demand response [30]. The policy makers, aggregators and utilities implement DR programs (tariffs and incentives) encourage energy consumers to participate [16] with their flexible energy consumption. Incentives can change the energy consumers' behavior [30]. There are mainly two types of energy flexibility programs: price-based and incentive-based programs. Price-based program includes RTP (real-time pricing) and the TOU (time-of-use) pricing [10]. Incentive-based program is DLC (direct load control) and direct participation to energy markets.

\section{Power System in the Philippines}

This section discusses the case of the power system in Philippines, and specifically investigates the current situation, the technology, influential factors and energy programs in Philippines to understand how a country copes with the growing demand for electricity and what role energy flexibility plays in the Philippines’ power system.

\subsection{Challenges in the Power System}

Philippines consist of many islands with a growing population and under-develop infrastructure. The reliance on fuel imports, low per-capita income, cost-reflective electricity and poor energy infrastructure are just few factors affecting the development of the power system in the Philippines.

Electricity Price. Philippines has one of the most expensive electricity prices in Asia [31]. Because the country is dependent on imported fuel and the government does not provide electricity subsidy. The private distribution utilities decide the electricity retail price according to locations and types of consumers. Luzon has an average electricity price of P9.15, P8.41 in Visayas and P7.15 in Mindanao (1 Euro $=52.62$ pesos) [32]. The average electricity price in Philippines for residential is P8.87, P9.14 for commercial and P6.87 for industrial [32].
Electricity Losses. The electricity loss is one of the challenges in the electricity system in Philippines. The annual electricity consumption increases in an average of $7 \%$ from 2001-2014 and an average of 11.5\% electricity loss in 2010 to 2014 [33]. The electricity loss in Philippines is higher compared to the US and Denmark where only 6\% in 2011 [34].

Electricity Supply and Demand. Out of a population of more than 100 million people, there are 16 million who are not connected to the electricity grid in Philippines [35]. The rapid population growth indicates an increase of electricity demand. There is $7 \%$ increase in the energy demand in Philippines [33]. In addition, series of power blackout experience in the Philippines between March and June in Luzon area in 2015 due to power shortage [36].

The total generation in 2013-2014 reached 152,527 GWh [33]. The renewable energy resources (hydro, geothermal, wind, solar and biomass) share $26 \%$ $(112,815 \mathrm{GWh})$ of the total energy generation in 2013-2014. While the non-renewable resources (Oil-based energy, natural gas and coal) share 74\% $(39,712 \mathrm{GWh})$ of the generation in 2013-2014 [33].

Lack of Funding. Insufficient funding is a particularly a major constraint to power system development in the Philippines. Private companies mostly dominate the country's energy system. The private companies like Meralco invest time and financial resources to upgrade the electricity infrastructure of the country. Meralco is the largest electricity distribution utilities in the Philippines.

Geographical Situation. Power system development in Philippines is a challenge as it consists of many islands. There are 7,100 islands in the Philippines, 2,800 islands are inhabited. Additionally, Philippines is prone to natural disasters as it is situated along a typhoon belt and the so-called ring of fire. The Philippines is experiencing frequent power outage especially during summer season wherein the temperature reaches up to 35 degrees affecting the operation of hydroelectric plants. 
The development of the HVDC submarine cable connecting Visayas and Mindanao encounters geographical location issues. The plan to establish 23 km submarine cable that connects Leyte (Visayas) and Surigao (Mindanao) [37], is expected to finish in 2018. However, during the hydrographic survey, NGCP (National Grid Corporation of the Philippines) discovers unexploded bombs and ordnance, shipwrecks and the planned submarine cable path lies near to an active fault lines which could break the submarine cable [37]. Therefore, NGCP needs to find another feasible route that will connect the two islands.

\subsection{Government Programs and Legislation}

Philippines established the EPIRA (Energy Power Industry Reform Act) law in 2001 to reduce the electricity cost and increase energy supply using renewable energy [38]. In 2008, the government established Republic Act 9513 offers fiscal and non-fiscal incentives to encourage energy consumers to generate renewable energy. For instance, non-fiscal incentives include FIT (Feed-In Tariffs), green energy option program and net metering for renewable energy [39]. Further, Energy Standards and Labelling Program for electrical appliances are one of the government's energy efficiency initiatives [40]. It means that appliance manufacturers have to meet up with the energy usage standards set by the government.

\subsection{Technology}

The Philippines slowly adapts renewable energy technologies such as solar panels and wind turbines. However, its growth is influenced by several factors (e.g. technological cost and government regulation). Although, Philippines utilize technologies in production, transmission and distribution of renewable and non-renewable resources, there are still many off-grid areas that suffer from power shortage. Therefore some off-grid areas are provided with fuel generators [41].
Luzon and Visayas are interconnected through HVDC links to share their electricity and participate in the WESM (Wholesale Spot Market). WESM is a real-time energy market, wherein the generation schedules to meet customers' demand for each hour of the day [42]. In addition, transmission network (NGCP) conducts a pilot project utilizing smart technologies (e.g. EMS, SCADA and ODCC) to monitor power grid activities [43].

Meralco deploys a 40,000 smart metering system as a pilot project. Meralco plans to install 3.3 million smart meters by 2024 [40]. Meanwhile, Meralco develops “MOVEApp" for consumers to track and manage energy consumption [40]. In addition, Meralco offers peak/off-peak or POP program [44].

Additionally, the Philippines slowly adapt energy storage technology. In 2015, Philippines installed the first $10 \mathrm{MW}$ battery-based energy storage system in Zambales to store surplus energy produced from the neighboring coal plant [45]. Meanwhile, a few pump hydro storages installed in Philippines such as Kalayaan Pumped-Storage Hydroelectric plant in Laguna.

\section{Energy Flexibility in Philippines' Power System}

Power losses, geographical location issues, lack of investment and power outage are just few challenges in the Philippines' power system. Philippines slowly improves flexibility in the power system by installing smart technologies such as HVDC, energy storage and demand response. Philippines still experiences imbalance in the power distribution. Philippines economy is underdeveloped, and private companies are more responsible compared to the government in investing energy flexibility. A summary of sources and solutions for energy flexibility challenges and technologies in Philippines is shown in Table 1.

\section{Discussion}

Energy flexibility provides balance between the 
Table 1 Technology and challenges in the Philippines' power system.

\begin{tabular}{|c|c|c|c|}
\hline Flexibility solutions & Technology & Challenges & Recommendation \\
\hline $\begin{array}{l}\text { Generation Units: } \\
\text { Generation plants, DG }\end{array}$ & Hydro power plants, DG & Energy supply & $\begin{array}{l}\text { Fast ramping energy units } \\
\text { DG }\end{array}$ \\
\hline Grid Infrastructure: & HVDC & Power losses & Single national grid \\
\hline HVDC, PSTs & SCADA, EMS & Geographical situation & Micro grid \\
\hline Energy Storage: & & & Shared energy storage systems \\
\hline Water heaters, Electric vehicles, Heat pumps, & Battery & Limited energy storage & Increase installation of energy \\
\hline $\begin{array}{l}\text { Pump hydro, compressed air, flywheels, } \\
\text { batteries }\end{array}$ & $\begin{array}{l}\text { Fuel tanks } \\
\text { Pump hydro storage }\end{array}$ & Lack of funding & $\begin{array}{l}\text { storage (e.g. pump hydro } \\
\text { storage) }\end{array}$ \\
\hline Demand Response: & Smart meters, Peak/Off & Price & Load management \\
\hline DR, smart meters & Peak, MOVEApp. & Power outage & Incentives \\
\hline $\begin{array}{l}\text { Market Operation: } \\
\text { Forecast Data } \\
\text { Dispatch Schedule }\end{array}$ & $\begin{array}{l}\text { Forecast Data, Dispatch } \\
\text { Schedule }\end{array}$ & Lack of funding & Improving grid infrastructure \\
\hline
\end{tabular}

energy supply and demand. There are different ways to achieve flexibility in the power system with the consideration of the national situation and influential factors:

Flexibility can be achieved through fast-ramping generation resources. In addition, flexible energy resources are able to hold energy levels for longer period, have greater ramp rates and able to adjust quickly to any change in the power system. In addition, the integration of distributed generation in the grid can enhance flexibility.

Developing a single national grid using HVDC. The plan of the Philippines to develop a single national grid that connects the three main islands can improve the energy market operation and provide a balance energy distribution in the country.

Load management practices or demand side management such as peak shaving can provide flexibility form the electricity consumption. In Philippines, government offers FIT program to energy generators and utilities with incentive programs such as Peak-Off-Pick, and buy back for energy consumers. However, there is no information that discusses the consumers' level of engagement to the programs. The government and utilities should encourage more consumers to participate in the demand programs to reduce energy consumption. To do this, the government and utilities can increase the awareness of the energy consumers on the global energy issues.

Investigation of the potential of the cost-effective energy storage such as pump hydro storage can keep the balance in the grid. Philippines have mountainous areas and different bodies of water (rivers, lakes, waterfalls and ocean) suitable for the energy storage. In addition, shared energy storage systems can provide high ROI, and allow optimization and exchanging minimal information among users. In addition, by optimizing the energy storage system's schedules and other building technologies can reduce the energy consumption.

Market operation can achieve flexibility by shortening the dispatch schedules and improving the weather forecasting. For example, providing an advanced information technology and improved grid infrastructure can improve the weather forecasting.

\section{Conclusions}

This paper concludes that the energy flexibility can address the energy inefficiency in Philippines by deploying energy flexibility solutions. The current energy programs in Philippines can reduce the electricity price and consumption, and involvement of energy consumers in the energy flexibility is important which is under-estimated in the Philippines' power system and market. Therefore, this paper suggests that further studies should focus more on the load management practices in Philippines.

\section{References}

[1] Bach, B., Wilhelmer, D., and Palensky, P. 2010. "Smart 
Buildings, Smart Cities and Governing Innovation in the New Millennium." In Proceedings of the 8th IEEE International Conference on Industrial Informatics, 8-14.

[2] Lannoye, E., Flynn, D., and Malley, M. O. 2011. “The Role of Power System Flexibility in Generation Planning." In Proceedings of the 2011 IEEE Power and Energy Society General Meeting, 1-6.

[3] Mishra, H. K. S., Palu, I., Kuhi-Thalfeldt, R., and Rosin, A. 2016. "Assessing Demand Side Flexibility with Renewable Energy Resources." In Proceedings of the IEEE 16th International Conference on Environment and Electrical Engineering (EEEIC), 1-6.

[4] Papalexopoulos, A., Hansen, C., Frowd, R., Tuohy, A., and Lannoye, E. 2016. "Impact of the Transmission Grid on the Operational System Flexibility." In Proceedings of the 2016 Power Systems Computation Conference (PSCC), $1-10$.

[5] Ma, Z., Friis, H. T. A., Mostrup, C. G., and Jørgensen, B. N. 2017. "Energy Flexibility Potential of Industrial Processes in the Regulating Power Market.” In Proceedings of the 6th International Conference on Smart Cities and Green ICT Systems, 109-15.

[6] Herten, J. V. D., Depuydt, F., Baets, L. D., Deschrijver, D., Strobbe, M., Develder, C., et al. 2016. "Energy Flexibility Assessment of an Industrial Coldstore Process." In Proceedings of the 2016 IEEE International Energy Conference (ENERGYCON), 1-6.

[7] Hippolyte, J. L., Howell, S., Yuce, B., Mourshed, M., Sleiman, H. A., Vinyals, M., et al. 2016. “Ontology-Based Demand-Side Flexibility Management in Smart Grids Using a Multi-Agent System.” In Proceedings of the 2016 IEEE International Smart Cities Conference (ISC2), 1-7.

[8] Kristiansen, M., Korp, M., Farahmand, E, H., Graabak, I., et al. 2016. "Introducing System Flexibility to a Multinational Transmission Expansion Planning Model.” In 2016 Power Systems Computation Conference (PSCC), 1-7.

[9] Wu, H., Shahidehpour, M., Alabdulwahab, A., and Abusorrah, A. 2015. “Thermal Generation Flexibility with Ramping Costs and Hourly Demand Response in Stochastic Security-Constrained Scheduling of Variable Energy Sources.” IEEE Transactions on Power Systems, 30 (6): 2955-64.

[10] Li, J., Wu, Z., Zhou, S., Fu, H., and Zhang, X. P. 2015. "Aggregator Service for PV and Battery Energy Storage Systems of Residential Building.” CSEE Journal of Power and Energy Systems 1 (4): 3-11.

[11] Lannoye, E., Flynn, D., and Malley, M. O. 2015. "Transmission, Variable Generation, and Power System Flexibility.” IEEE Transactions on Power Systems 30 (1): 57-66.

[12] Anwar, A., and Pota, H. R. 2011. "Loss Reduction of
Power Distribution Network Using Optimum Size and Location of Distributed Generation.” In Proceedings of the AUPEC 2011, 1-6.

[13] Cochran, J. E. A. 2014. "Flexibility in 21st Century Power Systems.” Denver, Colorado.

[14] Bresesti, P., Capasso, A., Falvo, M. C., and Lauria, S. 2013. "Power System Planning under Uncertainty Conditions. Criteria for Transmission Network Flexibility Evaluation." In Proceedings of the Power Tech Conference, 2003 IEEE Bologna 2: 6.

[15] Thakurta, P. G., Maeght, J., Belmans, R., and Hertem, D. V. 2015. "Increasing Transmission Grid Flexibility by TSO Coordination to Integrate More Wind Energy Sources While Maintaining System Security." IEEE Transactions on Sustainable Energy 6 (3): 1122-30.

[16] Wangdee, W., Billinton, R., Li, W., and Suwanasri, T. 2014. “Assessing Transmission System Flexibility Associated with Wind Power Integration Using Well-Being Analysis.” In Proceedings of the 2014 International Conference on Probabilistic Methods Applied to Power Systems (PMAPS), 1-6.

[17] Goutard, E., Passelergue, J. C., and Sun, D. 2013. "Flexibility Marketplace to Foster Use of Distributed Energy Resources." In Proceedings of the 22nd International Conference and Exhibition on Electricity Distribution (CIRED 2013), 1-4.

[18] Aggarwal, S., and Orvis, R. 2016. "Grid Flexibility: Methods for Modernizing the Power Grid.” Presented at Energy Innovation San Francisco, California March 2016.

[19] Jay, D., and Swarup, K. S. 2016. "Demand Response Based Automatic Generation Control in Smart-Grid Deregulated Market.” In Proceedings of the 2016 IEEE 6th International Conference on Power Systems, 1-8.

[20] Ma, Z., Billanes, J. D., Kjærgaard, M. B., and Jørgensen, B. N. 2017. "Energy Flexibility in Retail Buildings: From a Business Ecosystem Perspective.” In Proceedings of the 14th International Conference on the European Energy Market (EEM), Dresden, Germany, p. 6.

[21] Jianli, P., Jain, R., and Paul, S. 2014. “A Survey of Energy Efficiency in Buildings and Microgrids Using Networking Technologies.” IEEE Communications Surveys \& Tutorials 16 (3): 1709-31.

[22] Riaz, S., Chapman, A. C., and Verbi, G. "Evaluation of Concentrated Solar-Thermal Generation for Provision of Power System Flexibility.” In Proceedings of the 2016 Power Systems Computation Conference (PSCC), 1-7.

[23] Son, J., Hara, R., Kita, H., and Tanaka, E. 2014. “Energy Management Considering Demand Response Resource in Commercial Building with Chiller System and Energy Storage Systems.” In Proceedings of the 2014 International Conference on Power Engineering and Renewable Energy (ICPERE), 96-101. 
[24] Dimitrov, P., Piroddi, L., and Prandini, M. 2016. "Distributed Allocation of a Shared Energy Storage System in a Microgrid." In Proceedings of the 2016 American Control Conference (ACC), 3551-6.

[25] Mikoshi, T., Soeda, K., Takahashi, K., and Takenaka, T. 2014. "Improvement of Consumer Satisfaction Level by Energy Storage System in Smart Houses.” In Proceedings of the 20th Asia-Pacific Conference on Communication (APCC2014), 260-5.

[26] Ozdemir, E., Ozdemir, S., Erhan, K., and Aktas, A. 2016. "Energy Storage Technologies Opportunities and Challenges in Smart Grids.” In 2016 International Smart Grid Workshop and Certificate Program (ISGWCP), 1-6.

[27] Lynch, P., Power, J., Hickey, R., Kelly, D., Messervey, T., Manuel, J., et al., 2016. "Maximising Value for Local Flexibility Management in Low Voltage Distribution Networks." In Proceedings of the 2016 IEEE International Smart Cities Conference (ISC2), 1-6.

[28] Spiesova, D., and Maga, D. 2016. "Socio-Political View of Smart Grid Implementation: A Survey.” In Proceedings of the 2016 17th International Scientific Conference on Electric Power Engineering (EPE), 1-5.

[29] Torbaghan, S. S., Blaauwbroek, N., Nguyen, P., and Gibescu, M. 2016. "Local Market Framework for Exploiting Flexibility from the End Users." In Proceedings of the 2016 13th International Conference on the European Energy Market (EEM), 1-6.

[30] Mart, G., Liu, J., Li, B., Mathieu, J. L., et al., 2015. "Enabling Renewable Resource Integration: The Balance between Robustness and Flexibility.” In Proceedings of the 53rd Annual Allerton Conference on Communication, Control, and Computing (Allerton 2015), 195-202.

[31] Arangkada Pilipinas. 2016. Power Background. Available: http://www.investphilippines.info/arangkada/seven-winne rs/infrastructure/power/background/-fnote_83.

[32] DOE. 2012. “21st EPIRA Status Report.” D. D. o. Energy, Philippines, p. 120.

[33] DOE. 2014. “2014 Philippines Power Statistics.” Philippines 2014.

[34] World Bank. 2016. "Electric Power Transmission and Distribution Losses (\% of output).”
[35] Gonzales, I. 2013. 16-M Pinoys Do Not Have Access to Electricity Study. Available: http://www.philstar.com/business/2013/11/25/1260424/1 6-m-pinoys-do-not-have-access-electricity-study.

[36] Olchondra, R. T. 2015. Worst Case: 3 Months of Outages in 2015.2 Available: http://business.inquirer.net/180299/worst-case-3-monthsof-outages-in-2015.

[37] Gallardo, F. 2016. ERC Says Attempt to Link Mindanao and Visayas Power Grids Failed. Available: http://www.mindanews.com/top-stories/2016/01/erc-says -attempt-to-link-mindanao-and-visayas-power-grids-faile $\mathrm{d} /$.

[38] NEDA. 2001. Republic Act 9136. Edited by P. Congress, Philippines, p. 35.

[39] ERC. 2009. "RA 9513, Renewable Energy Act of 2008, IRR.” Philipiines.

[40] Metering.com. 2016. Energy Conservation and Grid Status in the Philippines. Available: https://www.metering.com/features/energy-conservationphilippines-analysis/.

[41] Miraflor, M. B. 2014, March 2016. NPC Starts Fuel Storage Upgrade for SPUG. Available: http://www.manilatimes.net/npc-starts-fuel-storage-upgra de-for-spug/75404/.

[42] TRANSCO. 2003. "Specific 'Timetable' to be Used in the Market as Mentioned in the Submission Detailing Activities on Each of the Period Specified.” October 21, 2003 Philippines: ERC, p. 9.

[43] Cuevas-Miel, L. 2014. NGCP to Pilot "Smart" Technology in Power Grid by 2016. Available: http://interaksyon.com/business/83421/ngcp-to-pilot-smar t-technology-in-power-grid-by-2016.

[44] Ranada, P. 2014. How Practical Is Solar Power for PH Home Owners? Available: http://www.rappler.com/ business/industries/173-power-and-energy/64165-solar-p ower-ph-households-net-metering.

[45] Micro Grid Media. 2015. AES Adding Battery Storage Capacity to Philippine Power Grids. Available: http://microgridmedia.com/aes-adding-battery-storage-ca pacity-to-philippine-power-grids/. 